\title{
CONSIDERACIONS \\ SOBRE EL PATRIMONI DELS ORDES MILITARS \\ A CATALUNYA \\ EN TEMPS DE RAMON BERENGUER IV
}

\author{
MARIA BONET DONATO \\ Universitat Rovira i Virgili
}

(Tarragona)

\section{SUMARI}

1. Els inicis de la implantació dels ordes militars.- 2. Acords pel testament del Bataller i projecció en terres conquerides.- 3. Les donacions: de la salvació de les ànimes a la consolidació de la feudalització.- 4. Cloenda.

En temps de Ramon Berenguer IV, templers i hospitalers esdevingueren institucions molt poderoses al Principat, com a causa i conseqüència d'un espectacular creixement patrimonial. Aquest es degué, en bona part, a l'actuació comtal, a un volum heterogeni de donacions, i també a la intervenció d'ambdós ordes. Les conquestes a la Catalunya Nova intensificaren l'expansió del patrimoni esmentat, resultat de les donacions de Ramon Berenguer IV i conseqüents amb els acords pel testament del Bataller, que paradoxalment trobaren una aplicació destacable a Catalunya. A més, els successos esmentats van marcar l'origen d'un període de llarga durada d'un segle i escaig, en què la monarquia situà el Temple i l'Hospital en l'avantguarda conqueridora. Per tot això, definirem aspectes relatius a la formació del dilatat patrimoni dels ordes al Principat durant el mandat del comte. En realitat, aquests estan emmarcats en una temàtica i uns àmbits

"Anuario de Estudios Medievales", 28 (1998) 
geogràfics i cronològics més amplis, però escapen a les possibilitats d'aquest estudi.

En la bibliografia d'ordes militars, l'època de Ramon Berenguer IV ha estat més estudiada que altres de posteriors, precisament per la seva transcendència, tot i que també és més controvertida, tant pels documents com per les interpretacions. Sense entrar en valoracions crítiques i de detall, cal destacar la importància iniciadora i difusora de J. Miret i Sans ${ }^{1}$. L'aportació d'A.J. Forey va ser capital, ja que va abordar la història dels templers a la Corona d'Aragó de forma exhaustiva, científica i renovadora ${ }^{2}$. Autors com S. García Larragueta i M.L. Ledesma Rubio, bons coneixedors dels ordes, encara que dedicats a Navarra i Aragó, van donar novetats sobre els orígens ${ }^{3}$. Els estudis de J.M. Sans Travé i L. Pagaroles sobre el Temple a Barberà i Tortosa han analitzat de forma crítica els primers temps a Catalunya. Recentment el mateix Sans Travé els ha ampliat en un llibre rigorós i de divulgació sobre els templers catalans ${ }^{4}$.

En aquest marc, s'abordaran algunes característiques de la formació patrimonial del Temple i l'Hospital, i sobretot aspectes menystinguts o poc tractats en la bibliografia; com per exemple l'anàlisi del com, el perquè i el paper de les donacions menors. L'estudi d'una part significativa de documents dels ordes en temps de Ramon Berenguer IV permet oferir

\footnotetext{
1910.

'Joaquim MiRET i SANS, Les cases de Templers y Hospitalers en Catalunya, Barcelona,

2Alan J. Forey, The Templars in the "Corona de Aragon", Oxford, 1973.

${ }^{3}$ Santos García larragueta, La Orden de San Juan en la crisis del Imperio Hispánico del siglo XII, "Hispania", 12, (1952), pp. 483-524; El Gran Priorado de Navarra de la Orden de San Juan de Jerusalen. Siglos XII y XIII, Pamplona, 1957; María Luisa LedESMA RUBiO, Templarios y hospitalarios en el Reino de Aragón, Zaragoza, 1982; jo mateixa en el llibre La Orden del Hospital en la Corona de Aragón, Madrid, 1994, vaig valorar les relacions entre el comte i l'Hospital a tall introductori de l'estudi, i per tant de forma poc aprofundida i millorable, però en mantinc les idees centrals. L'estudi monogràfic dels orígens del Temple de Peter SCHICKL, Die Entstehung und Entwicklung des Templerordens in Katalonien und Aragon, "Gesammelte aufsätze zur Kulturgeschichte Spaniens", 28 (1975), pp. 115-135, està ben documentat, però és poc innovador. Per una major informació bibliogràfica, cal consultar el complet i crític estat de la qüestió, Carlos DE AYALA i altres, Las Ordenes militares en la Edad Media peninsular. Historiografía 1976-1992, "Medievalismo", 1993, pp. 87-144.

${ }^{4}$ Josep M. Sans Travé, Alguns aspectes de l'establiment dels templers a Catalunya: Barberà, "Cuaderns d'Història Tarraconense", 1 (1977), pp. 9-59 i Els templers catalans, Barcelona, 1996; Laureà PAGAROLAS, La comanda del Temple de Tortosa: primer període (1148-1213), Tortosa, 1984.
} 
aquesta panoràmica del tema; però s'han deixat de banda alguns aspectes, episodis i referències bibliogràfiques en benefici de la síntesi ${ }^{5}$.

\section{ELS INICIS DE LA IMPLANTACIÓ DELS ORDES MILITARS}

La cronologia de la introducció dels ordes a Catalunya i a Aragó és polèmica, però el període del 1131 a 1134 va ser clau per a l'establiment definitiu al Principat; en part, mercès al suport manifest dels comtes d'Urgell i Barcelona. Anteriorment havien obtingut donacions, sobretot l'Hospital, que s'introduí a la Península per captar almoines entorn el 1113, va atreure béns en la dècada següent i s'hi establí en els primers trenta ${ }^{6}$. Quant al Temple, Forey rebutja dates anteriors al 1128, i qüestiona les del bienni posterior ${ }^{7}$. En tot cas, les primeres intervencions de tots dos a Catalunya al principi dels anys trenta perseguien obtenir recursos per Llevant ${ }^{8}$.

Els anys 1131 i 1132 succeïren fets transcendents que prefiguraven la importància que assolirien els ordes. El juliol de 1131 Ramon Berenguer III va deixar un mas al Sant Sepulcre; el seu cavall Danc, al Temple, i un mas de Vilamajor i un cavall negre, a l'Hospital en el testament. Les donacions, que no eren les primeres del comte per als hospitalers, tancaven una llarga llista de beneficis destinats a institucions eclesiàstiques, la qual cosa sembla indicativa de la consideració que els tenia. En tot cas, el comte

${ }^{5} S^{\prime}$ han consultat pergamins del fons del Gran Priorat de Catalunya de la secció d'ordes religiosomilitars de l'Arxiu de la Corona d'Aragó (des d'ara ACA, ORM, amb indicació numèrica d'armari i de pergamí); el cartulari de Gardeny (197) (des d'ara cartulari); així com els de Ramon Berenguer IV de la cancelleria (des d'ara ACA, RBIV, amb indicació numèrica de carpeta i pergamí). Salvador Cabré i Núria Grau, van fer el regest dels de cancelleria, que hem contrastat. A més, una part destacable de la documentació està publicada.

${ }^{6} J$ Jean Delaville Le Roulx, Cartulaire général de l'Ordre des Hospitalliers de Saint-Jean de Jerusalem (des d'ara Cartulaire), París, 1894-1906, I, pp. 30 i 12 (1102-1114). El 1134 s'hi instal.là definitivament, GARCíA LARRAGUETA, La Orden, pp. 486-87.

${ }^{7}$ FOREY, op. cit., pp. 6-9. De tota manera, el Temple va ser beneficiari de donacions menors als anys vint, com el 1124 quan obtingué amb l'Hospital i el Sant Sepulcre una mula, Agustí Altisent, Diplomatari de Santa Maria de Poblet (des d'ara Diplomatari) I, Barcelona, 1993 , p. 72

${ }^{8}$ García Larragueta, El Gran Priorado, p. 39 i Forey, op. cit., p. 28. 
manifestà el seu suport $\mathrm{i}$ deixà testimoni de la presència dels frares a Catalunya ${ }^{9}$.

Pocs dies després del testament, el comte professà el Temple, i li lliurà el castell de Granyena a la Marca, tot indicant la funció militar a desenvolupar ${ }^{10}$. Segons Sans Travé, la preferència pels hospitalers visible en el testament canvià envers als templers arrel de la visita de dos cavallers $^{11}$. Aquesta major estima inicial de Ramon Berenguer III per l'Hospital, coincidiria amb el bon acolliment entre feudals importants en els primers temps. Així ho corroboren donacions com la presumpta de l'església de Susterris pel bisbe d'Urgell el 1122 - confirmada el 1140 - o les posteriors dels comtes d'Urgell i de Pallars, més afeccionats als hospitalers que als templers ${ }^{12}$.

Pocs mesos després, el rei Alfons el Bataller deixà el regne d'Aragó als ordes del Sant Sepulcre, el Temple i l'Hospital, amb el propòsit, entre d'altres, d'implicar-los en les conquestes com ho prova el compromís d'eximir els templers de l'impost de la cinquena part del botí1 ${ }^{13}$.

Sembla que la proximitat entre les intervencions de Ramon Berenguer III i Alfons el Bataller a favor dels ordes militars no es poden deslligar, encara que no tenen cap relació aparent. Precisament el testament del rei aragonès i més indicis ens han portat a conjecturar que la professió de fe de Ramon Berenguer III al Temple l'hauria ideat el seu fill, per mostrar una vinculació del casal barceloní amb l'orde anterior al testament

${ }^{9}$ Pròsper de Bofarull i MASCARÓ, Colección de documentos inéditos del archivo general de la Corona de Aragón (des d'ara CoDoIn), IV, Barcelona, 1849, pp. 1-9. El mas de Vilamajor afrontava amb un altre donat pel comte anteriorment, i n'havia lliurat un a Sant Gilles, Cartulaire, p. 25 (1112-1128).

${ }^{10}$ Josep Maria SANS TRAVÉ (ed.), Col-lecció diplomàtica de la casa del Temple de Barberà (945-1212), Barcelona, 1997, pp. 101-102 (des d'ara Col-lecció). Aprofito per corregir el meu estudi de l'Hospital, on en aquesta i en una altra ocasió, s'indica, per error, aquest orde en comptes del Temple. Les donacions efectuades pels comtes de Pallars a Prim BERTRAN RoIGÉ, L'Orde de l'Hospital al comtat de Pallars (segle XII). Notes $i$ documents, "Analecta Sacra Tarraconensia", 53-54 (1983), pp. 221-251.

"SANS, Alguns aspectes, pp. 14-15.

${ }^{12} \mathrm{ACA}, \mathrm{GPC}, 2,120$ i MIRET, op. cit., p. 42. El bisbe de Barcelona, Arnal, mostrà simpatia per l'Hospital en deixar-li un mas en el testament, i en canvi ignorà al Temple, CodoIn, IV, pp. 81-84. Val a dir, però, que es redactà el 1142 en un moment de tensions entre els templers i el comte.

${ }^{13}$ CoDoIn, IV, pp. 9-12 i FOREY, op. cit., p. 17. 
d'Alfons, i presumiblement en el context de dificultats eventuals per a assolir els acords de renúncia ${ }^{14}$.

La donació del castell de Barberà de la Conca que va fer Ermengol VI, comte d'Urgell als templers el 1132 es relaciona amb els fets esmentats $^{15}$. Aquesta, com indica Sans Travé, s'assembla en la forma a la de Granyena, per exemple en l'atribució de la defensa de la Marca, i fins i tot hi ha fragments idèntics ${ }^{16}$. Una de les raons per explicar la similitud entre les dues donacions, i també amb la de Barberà feta per Ramon Berenguer IV als templers el 1135, és que la del 1132 servís de model per a les altres dues. De tota manera, en la carta de Barberà s'al-ludeix als homes del Temple que anirien a Granyena, fent-se ressò d'una vinculació del lloc amb l'orde anterior al 1132 -encara sense conseqüències - o de l'expectativa que es produís la donació. En canvi, el 1149, quan Bernat Isarn jurava fidelitat al comte per Granyena, no feia cap esment als drets dels templers, però curiosament es comprometia a fer hosts a terres andalusines amb cinc cavallers, en coincidència amb la funció militar prevista ${ }^{17}$.

Per comprendre el sentit d'algunes de les primeres donacions es referirà el context de la de Barberà. A la Conca, s'interseccionaren les expansions dels comtats d'Urgell i de Barcelona, la qual cosa creà contradiccions i divergències. Es van acabar, en gran mesura, després de la conquesta de Lleida, quan el comte Ermengol VI jurà fidelitat a Ramon Berenguer IV a canvi del feu d'un terç de Lleida. La cancelleria reial, per tal de donar caràcter d'antiguitat al vassallatge, falsejà una donació de Barberà del 1067 feta per Berenguer Ramon II a Ermengol IV d'Urgell, que hauria articulat la dependència feudal ${ }^{18}$. No obstant això, aquesta vinculació és provada, així com les intervencions del comtat de Barcelona a Barberà i a la

\footnotetext{
${ }^{14}$ Miret, op. cit., p. 23, plantejà la possibilitat d'una falsificació pels testimonis, documentats anys més tard, i la notícia ha arribat per trasllat -el més antic de finals del XII. A més, les referències, una del 1143, i als Gesta comitum procedeixen del regnat de Ramon Berenguer IV. Algunes situacions confirmen la possible falsedat de l'episodi, com, per exemple la sepultura del comte a Ripoll, complint el testament.

${ }^{15}$ Col-lecció, pp. 102-103; (ACA, RBIV, 34, 14).

${ }^{16}$ SANS, Els templers, p. 80.

${ }^{17} \mathrm{ACA}$, ORM, cartulari, 24r-v i 25r. La menció a casa templera no és fins al 1190, FoREY, op. cit., pp. 63 i 91 .

${ }^{18} \mathrm{El}$ comte de Barcelona, Ramon Berenguer I, va lliurar el lloc el 1055, la qual cosa prova el seu domini, però expressà certa prevenció sobre la possible intervenció d'un comte -cal pensar el d'Urgell-, Diplomatari, pp. 28-29.
} 
Marca ${ }^{19}$. A pesar d'això, en la donació del comte d'Urgell al Temple, no es feia cap esment al comte de Barcelona, ni tampoc en les darreres voluntats de Vidià el 1119 quan es referia a Barberà, que ho tenia per fevum de Ermengaudo comite $^{20}$. Sembla que el comte d'Urgell es desmarcà de la dependència, potser només teòrica, i actuà com a senyor, que va ser manifest en la projecció del comtat al Pla d'Urgell i altres llocs propers a Lleida

El 1135 el comte de Barcelona lliurava, novament, el castell de Barberà al Temple, ignorant la donació del comte d'Urgell i que fos feu d'aquell ${ }^{21}$. Per tant, la confirmació de Ramon Berenguer IV pot interpretarse dins d'un projecte més gran de dominar les terres ocupades i feudalitzades pel comte d'Urgell, com succeí després de la presa de Lleida. Aquest episodi és el primer testimoni d'una política desenvolupada per Ramon Berenguer IV i per altres feudals, segons la qual donaven als ordes militars llocs compromesos o en possessió d'altres vassalls. Els objectius eren diversos, però l'operació servia per reorganitzar els poders territorials en benefici d'un nou orde, on el comte es "resituava" com a màxim poder i tenia vassalls més fidels.

El 1133, en el testament d'Ermengol VI d'Urgell, l'Hospital obtenia un home en cadascun dels seus castells; i el Temple, les armes, el cavall, i els dominis de Calcines i Barberà. Altres donacions en el comtat d'Urgell, com la del castell i vil·la de les Ventoses de Guerau Pons, vescomte d'Àger, a l'Hospital el 1131, mostren com la donació de dominis importants als ordes per part del comte Ermengol o altres feudals foren anteriors a l'interès manifestat per Ramon Berenguer IV ${ }^{22}$. Aquest $s$ 'ha interpretat a remolc de les iniciatives del testament del rei aragonès i les del comte d'Urgell.

La preferència del Temple com a beneficiari d'armes i cavalls, de dominis en l'avançada cristiana o de la cinquena part del botí per part del Bataller, demostren la consideració d'aquest com a milícia per antonomàsia. Aquesta situació, però, no ha de servir per menystenir la valoració de l'Hospital com a orde militar per part dels contemporanis. Per això també va ser beneficiari de cavalls i en la mentalitat col-lectiva s'identificà amb el

\footnotetext{
${ }^{19}$ SANS, Alguns aspectes, pp. 21-27.

${ }^{20}$ Diplomatari, pp. 67-69.

${ }^{21}$ Col-lecció, pp. 103-104

${ }^{22}$ MiRET, op. cit., pp. 24-25 i 40-41 respectivament.
} 
Temple, com en els testaments en ambdós s'equipararen com a receptors ${ }^{23}$. De tota manera, aquesta valoració dels ordes no es traduí en intervencions militars fins als anys 1148-49, i s'inhibiren en la feudalització de l'avantguarda a Tarragona, o a les terres de Lleida, en progrés als anys trenta i quaranta.

La constitució de pau i treva d'abril de 1134, lliurada al Temple pel bisbe Oleguer, el comte de Barcelona i altres magnats és una fita transcendent en el seu establiment definitiu al Principat ${ }^{24}$. Tot $\mathrm{i}$ amb això, la confirmació de castells i propietats indica que la formació del patrimoni territorial havia començat, i que a més obtenia el suport dels màxims dignataris. Després de les signatures dels presents, Ramon Berenguer IV deixava el seu utillatge militar al Temple després de morir, a més d'una suma anual de diners. Sorprèn que es redactés al marge, i com un afegitó, una donació comtal orientada a manifestar la proximitat a l'orde. Encara és més estrany que es copiés en el dors, sense data ni signatures, la promesa del comte $\mathrm{i}$ alguns dels principals magnats catalans de servir per un any el Temple. Forey va plantejar que s'havia produït el mateix dia que l'assemblea; però no sembla lògic que una decisió important, presa en una reunió solemne, acabés copiada en el dors d'un document ${ }^{25}$. Podria tractar-se d'una incorporació posterior a la mort del Bataller, promoguda pel comte, per tal de palesar la seva inclinació pels templers en l'època que "festejava" el control del regne d'Aragó ${ }^{26}$.

De tota manera, cal destacar que Ramon Berenguer IV i alguns dels principals seguidors, com el Senescal, manifestaren la seva disponibilitat militar al Temple, a pesar del problema de la data, i fins i tot de la veracitat. Possiblement, certa precarietat inicial de mitjans de l'orde es resolia amb la

\footnotetext{
${ }^{23} \mathrm{Cal}$ advertir que en algun cas, el donador no coneixia bé què eren els ordes, com en un testament de 1133, en què l'Hospital i el Sant Sepulcre són esmentats com el mateix en dos ocasions: "...ipso cavallo Hospitale Sancti Sepulcri Iherosoliman et ad ipsa cavalleria similiter...", Diplomatari, pp. 82-83. La implicació més ràpida del Temple en qüestions militars es justifica d'acord a les diferències en la gestació dels dos ordes, Luís GaRCía GUIJARRO, Cruzadas, papado y órdenes militares, siglos XI-XIII, Madrid, 1995, pp. 123-124.

${ }^{24}$ Gener Gonzalvo I Bou, Les constitucions de Pau i Treva de Catalunya (segles XI-XIII), Barcelona, 1994, pp. 49-52.

${ }^{25}$ FOREY, op. cit., pp. 16 i 63.

${ }^{26}$ Les dues parts afegides van ser fetes, igual que la constitució per Pons, notari del comte, tot $\mathrm{i}$ que, la qualitat de la tinta sembla diferent, amb menys pigment $\mathrm{i}$ la lletra del dors no presenta la mateixa regularitat que la de l'assemblea. De manera que sembla que aquestes es van fer en un moment posterior.
} 
integració temporal dels cavallers. Potser també amb la mateixa finalitat, en la donació de Barberà es transferien al Temple els cavallers que tenien el domini de part del comte. Aquestes situacions són testimoni de certa permeabilitat entre la societat laica i els ordes en els primers temps, que desaparegué amb les primeres comunitats estables. La institució més representativa va ser la confraternitas, que vinculava cavallers i incorporava els seus béns ${ }^{27}$.

Després de la mort del Bataller, alguns magnats van fer donacions als templers i hospitalers, en les quals destaquem la possible intervenció, fins i tot pressió del comte. Ramon Berenguer IV consta com a testimoni en les de Pere Bertrà i Bernat de Belloc de l'església i dels alous de Sant Martí al Vallès el 1135, o la de Bernat d'un mas a Sant Andreu de Palomar el 1137 destinades al Temple, fetes pro anima ${ }^{28}$. Cal considerar l'impacte tant del testament com de les intervencions dels comtes, sobretot del de Barcelona, en l'increment notable de donacions en la segona meitat dels anys trenta $\mathrm{i}$ principis dels quaranta. Aquestes es produïren bàsicament al Vallès, al Penedès i a Osona, i confirmaven el fenomen, ja imparable, d'expansió patrimonial, perquè a més les primeres propietats n' "estiraren" d'altres ${ }^{29}$.

\footnotetext{
${ }^{27}$ Existiren també confrares hospitalers des de ben aviat, que s'esmenten en la donació del castell de les Ventoses el 1131 o en la d'un mas de Guillem de Berga, "prediciti Hospitale recollegimus in nostra societate quamodo boni amici et boni confrater", ACA, ORM, 3, 327 (1132).

${ }^{28} \mathrm{ACA}, \mathrm{RBIV}, 35,57$ i 74 respectivament. Pere Bertrà de Belloc havia assistit a l'assemblea de pau i treva del 1134, i també Berenguer de Queralt, que lliurà unes cases de Barcelona al Temple - amb signatures del comte i del bisbe Oleguer-, MIRET, op. cit., p. 25. Per tant, aquestes actuacions eren el resultat de les "fidelitats" dels grans senyors envers Ramon Berenguer IV.

${ }^{29}$ Algunes transmissions de propietat al Temple en els àmbits i cronologia esmentats: ACA 34, 32 (1132), 39 (1135), 44 (1134), 48 (1135), 49 (1135); 35, 52 (1136), 67 (1136); 36, 144 (1143); 146 (1142); 37, 153 (1143) i a l’Hospital ACA, ORM, 17, 243 (1138); 3, 266 (1141). Valgui com a testimoni de la concentració de patrimoni entorn a una unitat inicial la que es produí després de la donació d'un mas a Olèrdula a l'Hospital per Berenguer Bonfill el 1135 (ORM, 17, 510) amb la venda per part de Bernat Andreu dels alous a Olèrdula que tenia pel seu avi Berenguer Bonfill (ORM, 17, 246 -1137-) i altres com la d'un capmàs per Ramon Guillem d'Òdena (ORM, 3, 139 -1149-) i MIRET, op. cit. pp. 30 i 69.
} 


\section{ACORDS PEL TESTAMENT DEL BATALLER I PROJECCIÓ EN TERRES CONQUERIDES,}

Des del 1134 fins a la renúncia dels ordes al testament, Ramon Berenguer IV fomentà el seu desenvolupament i segurament per assolir el traspàs dels seus drets a Aragó, com ja s'ha indicat ${ }^{30}$. A partir dels acords pel testament del Bataller, aquests, sobretot el Temple, quedaren implicats en les futures conquestes ${ }^{31}$. En aquest sentit, els templers obtenien una cinquena part del que es conquerís, del botí - previst anteriorment pel Bataller- i els dominis de Barberà i Corbins, i els hospitalers van rebre un home de cada religió amb les propietats en les ciutats conquerides ${ }^{32}$. A més posteriorment, el comte plantejà la possible participació dels templers en les ràtzies a terres andalusines, quan els donà els musulmans que hi captures$\sin ^{33}$.

És difícil valorar la connexió entre els acords i les donacions posteriors a la conquesta, i de fet, com indica Forey aquestes eren conseqüència de les prestacions militars ${ }^{34}$. Sembla que la possibilitat d'obtenir - beneficis va ser el motor de la participació d'ambdós ordes en les empreses de Tortosa i Lleida $^{35}$. Anteriorment la seva activitat havia fomentat el creixement patrimonial a l'interior de Catalunya, fins i tot el Temple no s'havia introduit en les propietats de la Marca.

La conquesta significà el pas de templers i hospitalers de la rereguarda a l'avantguarda militar i del Principat, on obtingueren grans dominis. La nova situació els convertí en senyors importants en les terres

\footnotetext{
${ }^{30}$ Potser hi va haver preacords, com els referits en una petició del comte de 10 cavallers, que van atribuir a 1'Hospital, perquè la direcció recau en Raymundus que era el Mestre de l'Hospital i, a més, els acords afectaren aquest orde. Altres autors fan destinatari al Temple, com és raonable per la confirmació a Arnau de Bedós, CoDoIn, IV, 368-370. És un trasllat de 1311 , complex i sense data.

${ }^{31}$ MiRET, op. cit., p. 22, FOREY, op. cit., p. 23.

${ }^{32}$ Codoin, IV, 93-99 (1143) i 70-75 (1140) respectivament. El comte redactà unilateralment els acords amb els templers de 1143, en els que no renunciaren explícitament a Aragó ni signaren.

33"dono...sarracenos...quem de alias partes ibi aduxeritis vel de Ispania", ACA, ORM, cartulari, 23v - donació de Castellnou per Ramon Berenguer IV el 1146-.

${ }^{34}$ FOREY, op. cit., p. 24, encara que es refereix al Temple.

${ }^{35}$ BONET, op. cit., pp. 34-35, vam argumentar la intervenció dels hospitalers en les conquestes. Es podria considerar un altre testimoni indirecte a partir d'una donació, que en referia una de prèvia feta a Guillem de Belmes, prior d'Aragó i Bermud de Barcelona dos dies després de la conquesta de Tortosa, sembla que en el mateix escenari, ACA, ORM, 13, 139.
} 
conquerides, la qual cosa contribuí a accelerar el procés d'increment del patrimoni. Com observa Bertran Roigé, després de la conquesta de Lleida les propietats augmentaren de forma notable, sobretot respecte al període comprès des del testament d'Ermengol VI (1133) fins el 1149, caracteritzat per poques donacions ${ }^{36}$.

La proporció de terres obtingudes als territoris de Tortosa i Lleida pels templers és controvertida i difícil de mesurar, que a Tortosa oscil·la entre la quinzena part atribuïda per Miret a la cinquena per Forey, i a Lleida s'ha considerat la cinquena part de les dues terceres del comte de Barcelo$\mathrm{na}^{37}$. De fet, sembla raonable que a Tortosa fos també la cinquena de la part del comte, i fins i tot les proves aportades per Forey no ho desmenteixen. De tota manera, sembla que els templers reclamaren més terres a la regió, com ho provaria la seva renúncia a la cinquena part del castell i terme d'Amposta a favor dels seus propietaris, els hospitalers, el 1153. El comte intervingué en l'abandó de les exigències dels templers, fonamentades en la interpretació dels acords i també a conseqüència de la seva donació d'un amplíssim domini a la Ribera d'Ebre amb centre a Miravet dos mesos abans, per la destacada participació d'aquests en l'empresa ${ }^{38}$.

En els acords amb l'Hospital no es preveia la compensació de terres a Catalunya per la renúncia, però en canvi les conquestes s'acompanyaren de donacions. El dia de la rendició de Tortosa, l'orde obtingué diversos béns al Principat i a Tortosa mateix, confirmats el 1150 en una àmplia donació del terme d'Amposta, que vam relacionar amb la compensació territorial per la presa de Lleida. No sabem com es produí el salt des dels acords pel testament a la promesa de la desena part de les terres a conquerir als musulmans del $1157^{39}$. Ja anteriorment, en la concessió d'Amposta, el comte els donava la desena part de la seva part de les salines, la qual cosa mostraria un precedent o un testimoni d'algun pacte desconegut anterior al 1157.

És presumible que la donació d'Amposta i també la de la desena resultessin de les exigències dels hospitalers; potser en part, per la seva

\footnotetext{
${ }^{36}$ Prim BerTRAN I RoIGÉ, Per a un diplomatari d'Ermengol VII. Els ordes militars al comtat d'Urgell, "Ilerda", XLV (Lleida, 1984), p. 149.

${ }^{37}$ FOREY, op. cit., p. 25 i per Lleida, CoDoIn, IV, 126-9.

${ }^{38} \mathrm{~L}^{\prime}$ argumentació està a BONET, op. cit., pp. 35-36.

${ }^{39} \mathrm{ACA}, \mathrm{RBIV}, 40,317$ (CoDoIn, IV, 243-245) i RC, 287, 186v i 189r.
} 
situació d'inferioritat respecte als templers, com es deduiria del desfasament cronològic de les esmentades concessions comtals envers les primeres al Temple. Aquestes i altres de llocs encara per conquerir com Oropesa el 1150 proven que el comte confià en ells, al igual que en els templers, com a instruments òptims en l'avantguarda.

Com en altres indrets, les donacions de Ramon Berenguer IV al Temple i a l'Hospital esborraren promeses i compromisos anteriors a les conquestes que havia contret amb altres persones ${ }^{40}$. Aquest dinamisme en la dotació de propietats, fruit del poder de Ramon Berenguer IV i com a mecanisme per incrementar-lo, explicaria també els canvis posteriors a les conquestes, l'esvaiment dels acords pel testament, i la seva transformació i superació en escreix per a l'Hospital. En realitat, el comte utilitzà els ordes en benefici propi després de comprovar-ne la implicació militar, però a la vegada els situa al capdavant de grans dominis. La importància i la major cohesió dels nous envers els de la reraguarda explicaria també l'augment de la capacitat d'absorbir possessions i propietats veïnes ${ }^{41}$.

Les noves situacions creades a la Catalunya Nova també afectaren l'increment d'obtenció de patrimoni a llocs del rerepaís. Així, en la dècada dels cinquanta, una sèrie de donacions al comtat de Pallars contribuïren a la formació d'un domini a Susterris. L'origen era novament la intervenció del comte, Arnau qui el 1151 lliurà a l'Hospital el castell i vil la de Susterris, que s'amplià amb altres donacions i adquisicionss posteriors ${ }^{42}$.

\footnotetext{
${ }^{40}$ Entre els testimonis d’això esmentem la donació a Galindo Belxit de dues jovades a Benissanet (1148/9), que des de 1153 seria del Temple de Miravet, ACA. ORM, cartulari, 42 r-vi; o la donació d'Ascó a Ermengol d'Urgell en la convinença de Lleida, i precisament a canvi del quint, que seria del Temple ja en temps d'Alfons. Guillem de Sadao també obtingué cases a Ascó el 1152/3. cartulari, 53v. A tinals de IXXI, Ramon Berenguer III havia concedit Amposta a Artal comte de Pallars. que fou de l'Hospital. En la mateixa comarca, però posteriorment. el rei Alfons amplià el domini de l'orde amb la donació d'Ulldecona el 1178, on el 1167 Arnau de Jaca hi tenia un honor i drets en tot el terme central. Diplomatari, pp. 235-236.

"Els dominis dels templers a Tortosa i Gardeny deixaren nombrosos testimonis de l'activitat, gairebé depredadora en les propietats $\mathrm{i}$ explotacions agràries veïnes mitjançant compres o "donacions" en els anys cinquanta i següents. Destaquem aquí les adquisicions com a testimoni clar de l'interès i la capacitat de creixement de l'orde. En el cartulari de Gardeny - ACA - n'hi ha un bon nombre, ja sigui a feudals - a Bernat d'Anglesola, $15 \mathrm{r}-\mathrm{v}$ of $54 \mathrm{r}$ - $\mathrm{v}$ o Ramon de Sadao, $21 \mathrm{r}-\mathrm{v}-$, a petits propietaris i a altres (15r, 24r, 24r-v, 26r. 55r-v, 57r. 60v) que ho confirmen. El creixement del domini a Tortosa, on les compres es corresponien a la meitat d'adquisicions el detalla PAGAROLES, op. cit., p.83.
}

42ACA, ORM, 2, 4 i altres del comte a 2, 46 (venda d'un capmàs) i 2, 26 i 81 (donació a Talarn i confirmació de Susterris amb manament per fer església -1162-). 


\section{LES DONACIONS: DE LA SALVACIÓ DE LES ÀNIMES A LA CONSOLIDACIÓ DE LA FEUDALITZACIÓ}

L'època estudiada se situa al final d'un procés de llarga durada caracteritzat pel traspàs de propietat de possessors/propietaris a grans senyors, i especialment a institucions eclesiàstiques, sobretot a partir de la fórmula de les donacions per la salvació de l'ànima. Aquest fenomen culminà al segle XII, tot just quan els ordes protagonitzaren un creixement patrimonial extraordinari i únic, ja què es beneficiaren de l'esmentat traspàs i/o de la captació de propietats ${ }^{43}$. Aquest moviment els va permetre completar la condició de domini preminent en un territori, i consolidar el poder com a senyors feudals destacats.

Les donacions pro anima plantegen interrogants, perquè, sense negar les motivacions espirituals, és evident que hi intervingueren altres raons. És coneguda la confusió sobre el terme "donació", que s'utilitzava també com a sinònim de compravenda o permuta. De forma semblant, el concepte de donació per la remissió dels pecats s'usava de forma genèrica, i podia al-ludir a situacions creades per la intervenció irregular o arbitrària dels frares a fi d'augmentar el seu patrimoni. Aquestes formaven part del procés d'ampliació i/o coagulació de les seves propietats territorials, la qual cosa comportava la fixació o intensificació de les relacions de dependència entre la població i els feudals. En definitiva, els nous senyors, tot just arribats, culminaven la seva posició de domini, tot consolidant, o en altres llocs posant en marxa la feudalització del territori. Les donacions post obitum o reservato usufructo insinuen aquestes situacions, i demostren la precarietat dels benefactors envers les grans institucions religioses ${ }^{44}$. En algun cas, la donació comportava l'entrada en dependència dels antics propietaris com

\footnotetext{
${ }^{43}$ A nivell peninsular i des de feia dos centúries s'estava produint l'ampliació de dominis a costa de les petites propietats pageses i d'altres situacions, José Ángel GARCía DE CORTÁZAR, La sociedad rural en la España Medieval, Madrid, 1988, pp. 36-54.

${ }^{44} \mathrm{~A}$ vegades el donador mantenia la condició vitalícia de propietari -ACA, RBIV, 38, 217 (1140) per a la seva dona-, i d’altres conservaven la percepció d’algunes rendes com Bartomeu, el qual retingué la dècima de la propietat donada post obitum a l'Hospital (1150), ACA, ORM, 3, 352. Segons Paul H., FREEDMAN, Tradició i regeneració a la Catalunyal Medieval, Barcelona, 1985, p. 98, aquestes donacions condicionals, substituïren les simples des de finals de l'XI i el XII; encara que potser tan sols es posava per escrit una pràctica antiga.
} 
Guillem Ramon i muller, que al lliurar un alou de Sant Pere de Vilamajor al Temple quedaren com a tinents amb obligació de satisfer renda feudal ${ }^{45}$.

Entre les donacions votives, es diferencien les territorials i les de béns mobles pels orígens i les finalitats. Precisament la transcendència de les de béns immobles explica que se n'hagin conservat més escriptures. Ordinàriament en els testaments es deixaven béns mobles als ordes $\mathrm{i}$ altres institucions religioses, i tan sols en uns pocs al Temple i a l'Hospital en exclusiva. En algunes d'aquestes donacions privatives per ells es transmetien béns singulars com la somada de sal lliurada pel vescomte Bernat Amat el 1133, o els ramats de corders pel comte Artal de Pallars el 1157, àmbdues al Temple ${ }^{46}$. Són també característiques les donacions d'armes, cavalls i animals de tir als ordes, destinades en teoria a Terra Santa en els primers temps, i que després contribuïren als seus arsenals per als fronts croats al Principat ${ }^{47}$. També degueren servir per obtenir diners, que aconseguien directament per donatius pro anima com el de dos-cent sous de Guillem Humbert el 1134 al Temple i Hospital ${ }^{48}$.

Els testaments van aportar als frares la major part de béns mobles donats per redimir els pecats, que es repartien amb altres institucions eclesiàstiques, mentre què el patrimoni territorial es reservava gairebé sempre per a la família. El testador transferia intactes els dominis territorials a la seva descendència, i en conseqüència la seva posició social privilegiada. Aquesta actuació, fruit del sentit comú i/o de la necessitat, contribueix a dubtar del caràcter voluntari de les donacions, generalment per l'ànima, de terres als ordes i a altres institucions.

\footnotetext{
${ }^{45} \mathrm{ACA}, \mathrm{RBIV}, 34,8$ (1131) i MIRET, op. cit., p. 38. En una ocasió, la dependència de I'antic propietari es preveia vitalícia, com succé a Pere Veí, que havia de pagar una renda per explotar els alous que havia "donat" al Temple, ACA, RBIV, 36, 131 (1140). Sabem que, en realitat, Pere els havia venut amb més béns per 47 morabatins per "redimir els pecats", ACA, RBIV, 36, 123.

${ }^{46} \mathrm{ACA}, \mathrm{RBIV}, 34,33$ i ACA, ORM, cartulari, 42r.

${ }^{47}$ Els testaments de Gonbald i muller, els quals deixaven dos cavalls als ordes militars i altres béns mobles, o Guillem Dalmau, que Iliurà a l'Hospital i al Sant Sepulcre el cavall, armes i diners, tots dos el 1133, en són testimonis primerencs, Diplomatari, pp. $82-83$ i pp. 8486. El 1145, Pere de Berenguer donava la seva euga, la llança i l'espassa, ACA, RBIV, 37. 171; i Miró Rainer i Bengart d’Artesa lliuraren els seus cavalls i les armadures al Temple, ACA, ORM, cartulari, 61 v-62r (1153) i 55v. Abans de 1149, Ramon de Sa Rovira deixà el mul a I'Hospital, ACA, RBIV, 37, 158.

${ }^{48} \mathrm{ACA}, \mathrm{RBIV}, 34,35$, i 33 (1134) per una altra deixa.
} 
A vegades en els testaments, els benefactors ni tan sols diferenciaven entre els ordes, com Guillem, qui lliurà un terç als tres ${ }^{49}$. En alguns, s'explicitava la suma destinada a cadascun, gairebé sempre al Temple i a l'Hospital, com en el de Pere Maestre del 1139, en què deixava un morabatí a cada $u^{50}$. Per tant, reiterem que en les dècades dels trenta i quaranta no hi havia grans diferències en la mentalitat col-lectiva pel que fa a la consideració d'un o altre orde. Des de mitjans de segle, i per la formació de les primeres unitats destacables, les relacions de "veïnatge" ho modificaren en benefici de l'orde més proper.

Les donacions de diners o béns mobles, conegudes per testimonis dispersos, aportaren una font important de recursos en diners, i en conseqüència contribuïren a la "capitalització" de hospitalers i templers ${ }^{51}$. La seva liquiditat es manifestà en els processos d'expansió patrimonial des dels primers nuclis de propietat on compraren, permutaren i premiaren "donacions". A més, la disponibilitat de numerari dels ordes es confirma en la capacitat creditícia, coneguda al llarg de la seva història, i que es donà des de ben aviat. Així, Ramon Berenguer IV, i altres persones més modestes, obtingueren préstecs de l'Hospital ${ }^{52}$.

La renda feudal obtinguda en els diversos dominis era també una font de recursos convertibles en diners, i fins i tot en les primeres dècades obtingueren determinats drets sobre rendes en llocs aliens al seu domini. Valgui com a exemple d'aquesta peculiar situació la transmissió de delmes per part de senyors laics, encara que es pot dubtar de l'efectivitat de la

\footnotetext{
${ }^{49}$ ACA, RBIV, 38, 216 (1139). Pere Bernat testà vint morabatins al Temple i l'Hospital el 1162, Col-lecció, pp. 127-128. i Ramon Gausbert, dotze diners. ACA: RBIV. 36, 138 (1142). Fins i tot. en algun cas aillat els ordes militars obtenien conjuntament amb altres institucions eclesiàstiques una bona part dels béns mobles llegats pel testador. ACA. RBIV, C. 37.165 (1144).

${ }^{50}$ Diplomatari, pp. 91-92; el 1143 Bernat Arnau llegà 20 morabatins al Temple, una desena dels béns mobles per al Sant Sepulcre i una altra per a l'Hospital, Diplomatari, pp. 98-99. Guillem Berenguer deixava quatre morabatins a cadascun dels tres, ACA, RBIV, 39, 265 (1154). En rares ocasions, els testaments beneficiaren només un dels ordes, com Ermessenda que deixà un sou a l'Hospital el 1162. () Guillem dos terços dels béns mobles i una anualitat de dotze diners al Temple. ACA, ORM, 28, 8 i cartulari. 58r (1158).

${ }^{51} \mathrm{El}$ comte també els va fer importants donatius de diners, com els 1.000 morabatins de les pàries i 2.000 per a la construcció de la casa d’Amposta a l'Hospital, Cartulaire. I, pp. 141 i 142.

52BONET, op. cit., p. 36 i els préstecs dels templers al seu fill Alfons a MIRET, op. cit., pp. 106 i 107. Guerau de Sant Valentí i d'altres pignoraren el seu honor a l'Hospital a càrrec del préstec de setanta morabatins, ACA, ORM, 17, 244 (1143).
} 
percepció. El 1151 Guillem d'Aguiló va donar el delme de Benviure a l'Hospital i l'any següent, "curiosament" només la meitat".3. La possibilitat d'un moviment de "restitució" de prerrogatives de la jurisdicció eclesiàstica envers els seus representants, en aquest cas els ordes militars, es confirma per altres notícies ${ }^{54}$. La intervenció dels frares contribuí a aquest procés, com s'entreveu en el fet que els hospitalers de Cervera paguessin vint morabatins per l'apropiació del delme, la batllia i el districtum de Sa Rovira ${ }^{55}$.

Sembla que la intervenció dels ordes també va forçar altres donacions, a fi d'ampliar els seus drets jurisdiccionals. Així, el 1135 Arnau i altres lliuraven al Temple el dret de guaita que tenien al castrum callaris, on Pere Arnau, cavaller del Temple, hi tenia un alou. En aquest cas, com en d'altres, interpretem el veïnatge com un desencadenant, i no com a mer accident ${ }^{56}$. El 1139 Ramon de Subripàs i família renunciaven als drets de batllia i forcia al mas de Sargantanes i sobre els seus homes, pels quals havien mantingut diferències amb el Temple. També Raimon Gerard, reus et peccator, n'havia tingut amb la casa de Cervera de l'Hospital pel districtum et senioraticum, i s'acabaren amb la seva renúncia a tots els drets jurisdiccionals sobre les vinyes en litigi $\mathrm{i}$ altres donacions de censos i terres el $1157^{57}$. Aquestes situacions mostren com els ordes militars, quan s'establien en territoris feudalitzats des de temps anteriors, arrancaven diversos drets a senyors o als dependents per tal d'ampliar les competències jurisdiccionals.

De la mateixa manera, algunes donacions votives de béns territorials foren conseqüència de la gerència dels ordes, que van forçar als donadors o bé van compensar-los amb pagaments. Des de les primeres unitats patrimonials, templeres i santjoanistes van desenvolupar un procés d'absorció de propietats veïnes, fruit d'un model de "racionalitat" d'explotació econòmica,

\footnotetext{
${ }^{53} \mathrm{ACA}$, ORM, 13, 101 i 100 respectivament, MIRET, op). cit.. p. 68 . El 1141 Ermegarda i fills feien donació del delme d'un alou al terme de Olèrdola. Collecció, p. 109.

${ }^{54}$ Valgui com a exemple la Ramon Guillem d’Òdena va donar a l'Hospital de béns a Castellnou de Pontons, amb menció específica a l'església $i$ a tots els seus drets - delmes. primicies. rendes-, així com a les sufragànies. el 1138. ACA. ORM. 17. 457 i MIRET. op. cit. p. 30.

${ }^{55}$ ACA. ORM, 3. 261 (1154), i MIRET. (1). (it. . p. 69.

"ACA. RBIV, 34, 47

${ }^{57}$ ACA. RBIV. 36. 103 i ORM. 13. 265. respectivament.
} 
que ocasionà noves dependències entre els habitants i l'orde ${ }^{58}$. El 1146 Ramon Bernat de Gurb i muller donaren al Temple un honor a la parròquia de Sant Esteve de Granollers, afrontat amb una propietat templera a canvi d'un alsberg i una brandonera. A més, els donadors es comprometien a ajudar-los $\mathrm{i}$ a defensar-los contra cunctos homines ${ }^{59}$. La clàusula final empra termes específics d'una relació vassallàtica i podria fer al-lusió a una dependència amb aquestes connotacions, però també podria ser una fórmula per referir-se al compliment de la donació per part dels benefactors ${ }^{(0)}$.

En el mateix àmbit de Granollers, la captació de propietats dels templers va atreure la donació, també pro anima, de les terres del prevere Guillem a condició de què les treballessin els seus germans i nebots a canvi del cànon d'una quarta part dels fruits. Per tant, es creava una dependència entre els nous propietaris i tinents, però de caràcter diferent a l'explicada anteriorment. Guillem, el prevere, la va reforçar amb una altra deixa d'un alou, a canvi que germans i nebots quedessin com a donats en el convent del Temple $^{61}$. La nova vinculació personal garantia la relació de dependència fixada amb la primera donació, però en tenia un cost extraordinari. De fet, era comú que els donats aportessin terres en ingressar, com Guillem Folch que es lliurà a l'Hospital amb una jovada' ${ }^{62}$. De manera similar, però entre els privilegiats, els vinculats com a confrares o cavallers i les seves famílies feien importants donacions patrimonials als ordes ${ }^{6.3}$.

\footnotetext{
${ }^{58}$ En la formació patrimonial de la comanda templera de Tortosal. les compres i les permutes procuraren concentrar al maxim les propietats "per obtenir un millor benefici", segons observa amb encert PAGAROLES. op. cit. pp. 83 i 84.

5"ACA, RBIV. 37, 200.

${ }^{\left({ }^{(n)}\right.}$ En alguns actes de compres dels templers tortosins es troben expressions properes i pròpies de relacions vassallàtiques. com en la de Pere Guillem i muller, els quals després de vendre un camp indicaven "et nos gariremus et defendemus eam vobis ab omni homini". PAGAROLES, op. cit., p. 177 (1155). També en dues vendes realitzades per Martí Gòlia el 1157 hi ha frases similars precedides per com'enimus - amb connotacions feudovassallatiques-. PAGAROLES, pp. 179-180 i 183.

"ACA, RBIV, 38, 239 (1151) i 240 (1151), respectivamemt.

(2MIRET. op. cit., p. 35.

". Ramon Arnau de Bedós lliurà diverses propietats al Temple perquè el seu fill era confrare, ACA, RBIV, 34, 16 i SANS TRAVÉ, Els templers, p. 80. Berenguer de Sa Rovira, germà de Pere de Rovira, primer mestre provincial. i ell mateix, vinculat al Temple, van fer importants donacions, ACA. RBIV. 35. 7I (1137) i ACA. RBIV. 36. 120. 120 dup. (1140) i el seu fill. Ramon de Sa Rovira, les confirmà en el seu testament $i$ hi afegi altres béns, ACA, RBIV. 37. 158 (1144).
} 
La incorporació de terres veïnes, sota la fórmula de les donacions per l'ànima, comportà pagaments compensatoris que fins $\mathrm{i}$ tot podrien suggerir una venda forçada. En ocasions, es deixava constància què es tractava d'una donació sense més, tot i que era una venda. Això es palesa en una pro anima d'una peça de terra a Fontanet feta per Berenguer d'Oliola als templers el 1158 i limítrofa les terres d'ells. Com a nota marginal del document, es traslladà una àpoca de vint morabatins rebuts per l'esmentat Berenguer de mans del Temple, i encara que no s'explicités, era per la donació ${ }^{64}$. A vegades, la contrapartida lliurada per l'orde, s'expressava sota la fórmula de caritat, la qual cosa també desdibuixava la realitat de la transacció $^{65}$. De tota manera, algunes intervencions dels ordes tenien connotacions "caritatives", com en l'obligació dels templers de vestir i alimentar Sança després que els traspassés el seu honor el 1136, modalitat de dependència que sembla molt precària per a ella ${ }^{66}$.

És possible intuir la intervenció dels frares a favor dels seus interessos, fins $\mathrm{i}$ tot en situacions tan clarament d'intercanvi com les permutes. El 1148 els templers van permutar el mas de Guillem de Balanyà, que prèviament aquests havien redimit d'una pignoració ${ }^{67}$. No sembla que fos un simple recordatori, sinó una precisió per induir al canvi.

Algunes diferències sorgides a partir de testaments o donacions mostrarien també la complexitat del fenomen de transmissió de la propietat per part dels laics, i la possible pressió dels frares en el procés. El 1150 Ramon Berenguer de Gurb i muller renunciaven al seu alou, que Pere Vell havia lliurat en testament al Temple a Sant Esteve de Parets, a canvi de 200


terra al terme de Fontanet a canvi de cent sous. una mula $i$ un ruc, cartulari. 23v-24r (1162), que anteriorment les havia venut sense esmentar que fossin una donació votiva i en condicions diferents, cartulari, $21 \mathrm{r}-\mathrm{v}$ (1155). Al terme de Fontanet, els templers de Gardeny desplegaren un programa de compres per ampliar la seva propietat. Algunes vendes procedien de feudals importants com dels Anglesola el 1160, o Gonbald de Ribelles el 1153, que cobraren cinquanta morabatins, cartulari, $15 \mathrm{r}-\mathrm{v}$ i $15 \mathrm{v}$. La de 1160 mostra clarament com imperà un criteri de racionalitat econòmica perquè "afrontat istam honorem de tres partes in nostrum honorem de domui Templi".

${ }^{65} \mathrm{ACA}$, ORM, cartulari, 35v: i 36r (1167). Berenguer de Granyana donava per la remissió dels pecats un hort que afrontaval per dos costats amb els templers de Gardeny i alccipio de caritate... una bona mula cum una sella et cum un escut".

"ACA, RBIV, 35, 67.

${ }^{67}$ ACA, RBIV, 38, 204.
} 
sous per acabar amb les desavinences ${ }^{68}$. En algun cas, només coneixem la renúncia de laics sobre propietats per les quals havien litigat o lluitat amb els ordes, com el mas d'Arnau de Riera i Bernat i Guillem lliurat als templers a canvi d'una compensació de 35 sous $^{\text {(19}}$.

Hem valorat una sèrie de donacions o vendes de particulars nascudes dels interessos de templers i hospitalers, però lògicament també n'hi hagueren de motivades per les necessitats dels particulars, $i$ altres procedents de feudals destacats, més ajustades a una donació pròpiament dita. Valgui com a exemple de transaccions ocasionades per la necessitat la venda d'un honor a Sant Vicenç de Jonqueres per Pere, Berenguer i Pons de Fonollar a canvi d'un cavall, valorat en quaranta morabatins, que es produí

durant el setge Tortosa, i potser per a seguir lluitant ${ }^{70}$

\section{CLOENDA}

El complex fenomen de formació patrimonial es pot dividir en tres períodes, el primer introductori fins el 1134 en el qual es produïren les primeres donacions, entre les que n'hi havia de feudals importants. Després i fins el 1148, aquestes augmentaren de forma destacada, i els ordes fixaren dominis a la Catalunya central (Vallès, Osona, Penedès, Segarra, etc.). Des d'aquests, es produïren les seves primeres intervencions per tal d'atreure o sostreure les donacions pro anima, que completaven el seu patrimoni o drets jurisdiccionals. A més i paral-lelament, la seva introducció comportà una reorganització de les relacions de dependència en benefici seu, i un "perfeccionament" d'antigues ordenacions feudals. Totes aquestes actuacions de templers i hospitalers significaren una major i millor operativitat del

${ }^{6}$ ACA. RBIV, 38, 231. Ermessenda litigà pels seus drets en diversos indrets del Temple i l'Hospital. que els havia donat Dorca. A la fi. ella i fill renunciaren a la major part a canvi d'uns quants diners i una tercera part d'una parcel.la de terra. ACA. RBIV. 37. 177 (1145). Bernat Arnau es resistí a acceptar que la donació que ell havia fet a Sant Esteve de la Seu fós traspassada als templers, i obtingué dues fanegues d'ordi per la renúncia, ACA, 36, 149 (1143).

${ }^{61} \mathrm{ACA}, \mathrm{RBIV}, 39,272$ (1154). Altres diferències per la propietat o possessió de la terra linalizaren a favor dels templers, encara que curiosament com en els anteriors, en ocasions els frares compensaven economicament al qui perdia els drets. Fins i tot. quan aquest reconeixia iniuste contra eos tenebam. ACA. ORM. cartulari. 22v: i altres a $24 v$ o RBIV, 41. 2503.

7"ACA. RBIV. 38. 222. El 1142 s havia efectuat una primera donació-venda a canvi de trenta morabatins. que no es degué executar segons la segona operació el 1148. ACA. RBIV. 36. 146. 
poder feudal, que podríem valorar com una "refeudalització" dels espais on s'establiren.

En aquest segon període, el suport de Ramon Berenguer IV va ser clau, que inicialment era una estratègia d'aproximació, sobretot envers al Temple, per a obtenir la seva renúncia a Aragó. Després dels acords, els interessos del comte sintonitzaren amb els dels ordes i els situà en l'avantguarda del país. Com a conseqüència d'això s'entrà en un nou període o tercer, des de 1148 i en endavant, que es caracteritzà per la dotació dels grans dominis a la Catalunya Nova per part del comte, des d'on els frares desenvoluparen una important captació de terres orientada a la concentració de patrimoni, més activa que mai anteriorment. A més, el creixement patrimonial s'accelerà arreu com a l'Urgell o al Pallars.

En definitiva, els interessos, les estratègies i les intervencions del poder feudal articularen importants nous dominis en mans dels ordes, que per la seva condició d'eclesiàstics, militars i nouvinguts foren molt apropiats per a la reorganització dels espais feudalitzats i per als que es feudalitzaren.

\section{RÉSUMÉ}

À l'époque de Ramon Berenguer IV. les templiers et les hospitaliers ont joué un rôle important et ont augmenté leur patrimoine. De grands seigneurs féodaux ont fait des premiers dons avant 1134. et jusqu en 1148. ceux-ci sont accrus considérablement. À cette époque, les ordres ont implanté leurs domaines dans la Catalogne centrale et ont attiré ou forcé les premiers dons pro anima dans le but de parachever les droits juridictionnels et surtout patrimoniaux. Le soutien de Ramon Berenguer IV a été déterminant, bien quau départ, il s’agissait d'une stratégie visant une approche vers le Temple. Suite aux accords testamentaires, les intérêts du comte ont rejoint ceux des ordres qui. dès lors. ont été à l'avant-garde du pays dès 1148. C'est la dernière période de lintroduction des ordres dans la Principauté et le moment où le comte a enrichi la Nouvelle Catalogne de grands domaines. d'où les chevaliers ont développé un labeur de conquête de terres dans le but de rassembler leur patrimoine. En fait. les intérèts. les stratégies et les interventions du pouvoir féodal ont domné aux ordres d'importants nouveaux domaines, qui. vu leur idiosyncrasie. ont été propices à la réorganisation des fiefśs et aux intérêts de ceux qui les ont créés.

\section{SUMMARY}

The patrimony and prominence of templars and hospitallers increased dramatically in the time of count Ramon Berenguer IV. Feudal lords made their first donations before 
1134 and there were considerable increases from that year until 1148. During this period, these orders settled in central Catalonia, where they attracted or forced donations pro anima to assure their jurisdictional and. especially. their patrimonial rights. The count's support in this was crucial although initially it was merely an attempt to find favour. particularly with the templars. Following the testamentary agreements. the count's interests coincided with those of the orders and this positioned them at the vanguard of the country from 1148 onwards. In this period, the orders consolidated their position in the principality and the count granted them the large territories of "Catalunya Nova", from where the knights increased their patrimony by accumulating more land. The interests. strategies and actions of the feudal authorities placed important new domains in the hands of the templars and hospitallers who, because of the very nature of their orders. were in fact ideal for reorganizing both the lands and peoples recently brought under feudal control. 